\title{
1 Effects of the Background Electrolyte on Th(IV) \\ 2 Sorption to Muscovite Mica
}

3 Moritz Schmidt ${ }^{a,}$, Stefan Hellebrandt ${ }^{a}$, Karah E. Knope ${ }^{b, 1}$, Sang Soo Lee ${ }^{b}$, Joanne E. Stubbs ${ }^{c}$, Peter J.

$4 \quad$ Eng $^{c}$, L. Soderholm ${ }^{b}$, Paul Fenter ${ }^{b}$

$5 \quad{ }^{a}$ Helmholtz-Zentrum Dresden-Rossendorf, Institute of Resource Ecology, Dresden, Germany

$6 \quad{ }^{b}$ Chemical Sciences and Engineering Division, Argonne National Laboratory, Argonne, IL, USA

$7 \quad{ }^{c}$ Center for Advanced Radiation Sources, University of Chicago, Chicago, IL, USA

$8 \quad{ }^{I}$ Current address: Department of Chemistry, Georgetown University, Washington, DC, USA.

9 *Corresponding author. Phone: +49 351260 3136, E-Mail Address: moritz.schmidt@hzdr.de (Moritz

10 Schmidt).

ABSTRACT

The adsorption of tetravalent thorium on the muscovite mica (001) basal plane was studied by Xray crystal truncation rod (CTR), and resonant anomalous X-ray reflectivity (RAXR) measurements and alpha spectrometry in the presence of perchlorate background electrolytes $\mathrm{LiClO}_{4}, \mathrm{NaClO}_{4}$, and $\mathrm{KClO}_{4}([\mathrm{Th}(\mathrm{IV})]=0.1 \mathrm{mM}, \mathrm{I}=0.1 \mathrm{M}$ or $0.01 \mathrm{M}, \mathrm{pH}=3.3 \pm 0.3)$. RAXR data directly reveal a strong influence of the background electrolyte on the actinide sorption. No significant Th adsorption was observed in $0.1 \mathrm{M} \mathrm{NaClO}_{4}$, i.e., the Th coverage $\theta(\mathrm{Th})$, the number of Th per unit cell area of the muscovite surface $\left(\mathrm{A}_{\mathrm{UC}}=46.72 \AA^{2}\right)$, was $\leq 0.01 \mathrm{Th} / \mathrm{A}_{\mathrm{UC}}$, whereas limited uptake $\left(\theta(\mathrm{Th}) \sim 0.04 \mathrm{Th} / \mathrm{A}_{\mathrm{UC}}\right)$ was detected at a lower ionic strength $(\mathrm{I}=0.01 \mathrm{M})$. These results are in stark contrast to the behavior of $\mathrm{Th}$ in $0.1 \mathrm{M} \mathrm{NaCl}$ which showed a coverage of $0.4 \mathrm{Th} / \mathrm{A}_{\mathrm{UC}}$ (Schmidt et al., 2012a). Th uptake was also influenced by the electrolyte cation. Weak adsorption was observed in $0.1 \mathrm{M} \mathrm{KClO}_{4}\left(\theta(\mathrm{Th}) \sim 0.07 \mathrm{Th} / \mathrm{A}_{\mathrm{UC}}\right)$ similar to the results in $\mathrm{NaClO}_{4}$ at lower ionic strength. In contrast, strong adsorption was found in $0.1 \mathrm{M} \mathrm{LiClO}_{4}$, with $\theta(\mathrm{Th})=4.9 \mathrm{Th} / \mathrm{A}_{\mathrm{UC}}$, a $\sim 10$-fold increase 
compared with that previously reported in $\mathrm{NaCl}$. These differences are confirmed independently by $e x$ situ alpha spectrometry, which shows no measurable Th coverage in $0.1 \mathrm{M} \mathrm{NaClO}_{4}$ background in contrast to a large coverage of $1.6 \mathrm{Th} / \mathrm{A}_{\mathrm{UC}}$ in $0.1 \mathrm{M} \mathrm{LiClO}_{4}$. The CTR/RAXR analyses of Th- $\mathrm{LiClO}_{4}$ show the sorption structure consisting of Th species that are broadly distributed, centered at heights of $4.1 \AA$ and $29 \AA$ distance from the interface. Neither the very large distribution height of the second species nor the high coverage can be explained with (hydrated) ionic adsorption, suggesting that the enhanced uptake is presumably due to the formation and sorption of Th nanoparticles.

\section{INTRODUCTION}

Thorium is a primordial $\left(\mathrm{t}_{1 / 2}\left({ }^{232} \mathrm{Th}\right)=1.4 \times 10^{10} \mathrm{y}\right)$ member of the actinide series that occurs naturally in considerable amounts (11 ppm in the earth's crust). Thorium is the largest, chemically "softest", and least polarizing tetravalent cation, and as such least likely to undergo hydrolysis and subsequent condensation reactions (Baes and Mesmer, 1976; Burgess, 1978). The stable $[\mathrm{Rn}]^{0}$ electron configuration of Th(IV) also prevents any redox chemistry, and in aqueous solution only the tetravalent state of thorium is stable (Wickleder et al., 2011). Nevertheless, Th solution chemistry, while simpler than for the other actinides, still requires careful accounting for complexation, hydrolysis, and subsequent oligomerization. These reactions and their thermodynamics have been studied in great detail (Baes et al., 1958; Brown et al., 1983; Ekberg et al., 2000; Felmy et al., 1991; Knope and Soderholm, 2012; Knope et al., 2011; Neck et al., 2002; Rand et al., 2008; Ryan and Rai, 1987; Walther et al., 2008; Wilson et al., 2007), and it has become increasingly clear that condensation reactions can significantly impact Th(IV) solution chemistry, even at relatively low $\mathrm{pH}$ and low $\mathrm{Th}$ concentration.

There is a wide range of studies aiming to quantify the sorption of Th on various natural and synthetic minerals (Guo et al., 2005; Jakobsson, 1999; Landa et al., 1995; Li and Tao, 2002; Rojo et al., 2009; Sharma et al., 2009; Sharma et al., 2006; Sheng et al., 2008; Talip et al., 2009; Zhang et al., 2006). Several studies have attempted to gain a more mechanistic understanding through the use of advanced spectroscopic techniques (Östhols, 1995; Östhols et al., 1997), or surface complexation modelling (Reiller et al., 2005). However, little attention is usually given to the choice of background 
electrolyte. Many studies are performed in $\mathrm{NO}_{3}{ }^{-}$media (Guo et al., 2005; Li and Tao, 2002; Reiller et al., 2005; Sharma et al., 2009; Sharma et al., 2006; Sheng et al., 2008; Talip et al., 2009; Zhang et al., 2006), presumably due to its relevance in chemical-separations processes and its ubiquitous presence in groundwater. Studies in $\mathrm{ClO}_{4}{ }^{-}$media are also commonly found (Jakobsson, 1999; Östhols, 1995; Östhols et al., 1997; Reiller et al., 2005; Rojo et al., 2009). Only one study (Jakobsson, 1999) investigated sorption reactions for multiple background electrolytes, namely $\mathrm{NaCl}$ and $\mathrm{NaClO}_{4}$ (in this case on $\mathrm{TiO}_{2}$ substrates). The reaction is found to be independent of ionic strength and an effect of the change of media was not discussed.

The adsorption behavior of tetravalent Th on muscovite mica has been observed from $\mathrm{NaCl}$ media using alpha spectrometry and resonant anomalous X-ray reflectivity (RAXR) (Schmidt et al., 2012a). The study finds that sorption occurs in two distinct regimes. At low concentrations $([\mathrm{Th}]=$ $1 \times 10^{-6}-1 \times 10^{-3} \mathrm{~mol} / \mathrm{L}, \mathrm{pH}=3.2$ ) sorption can be described by a Langmuir-type sorption isotherm that yields a sorption constant of $\log \mathrm{K}_{0}=6.6 \pm 0.2$ and a maximum coverage of $\theta_{\alpha}=0.21 \mathrm{Th} / \mathrm{A}_{\mathrm{UC}}$ (number of Th atoms per area of the unit cell). At higher concentrations $\left([\mathrm{Th}] \geq 2 \times 10^{-3} \mathrm{~mol} / \mathrm{L}\right)$ a steep increase in surface coverage is observed (i.e. $\theta_{\alpha}>2 \mathrm{Th} / \mathrm{A}_{\mathrm{UC}}$ ), well beyond the amount of $\mathrm{Th}$ required for surface charge compensation $\left(\theta=0.25 \mathrm{Th} / \mathrm{A}_{\mathrm{UC}}\right)$. These results were speculated to be due to an oligomerization reaction of $\mathrm{Th}(\mathrm{IV})$ at the mineral-solvent interface. A similar, though more pronounced reaction has been observed for plutonium at the same interface (Schmidt et al., 2013). Specular X-ray reflectivity and RAXR at the muscovite $(001)-1 \times 10^{-4} \mathrm{~mol} / \mathrm{L} \mathrm{Th}(\mathrm{IV})$ solution (i.e., within the "Langmuir regime") interface revealed that Th(IV) adsorbs dominantly as a hydrated extended outer sphere complex (Lee et al., 2010; Schmidt et al., 2012a). This Th species is distributed broadly with an average height $\sim 10 \AA$, too large to be either an inner or outer sphere sorption complexes, which would be expected at $\sim 2 \AA$ and $\sim 4 \AA$, respectively.(Lee et al., 2010) The coverage found in the in situ RAXR experiments $\left(\theta_{\mathrm{RAXR}}=0.4 \mathrm{Th} / \mathrm{A}_{\mathrm{UC}}\right)$ was slightly larger than what was found in the ex situ alpha spectrometry quantification. This difference may result from the washing step, applied prior to ex situ alpha spectrometry, which can remove some weakly-bound Th from the surface. The $\theta_{\text {RAXR }}$ value is larger than the amounts needed for the compensation of the muscovite 
surface charge (i.e., 0.25 or $0.33 \mathrm{Th} / \mathrm{A}_{\mathrm{UC}}$ for $\mathrm{Th}^{4+}$ or trivalent $\mathrm{Th}$ species, respectively, the two major Th species in the bulk solution), indicating that adsorbed Th overcompensates the mineral's surface charge.

Here, we demonstrate that Th sorption at the muscovite-water interface is strongly influenced by the choice of background electrolyte $\left(\mathrm{NaCl}, \mathrm{LiClO}_{4}, \mathrm{KClO}_{4}\right.$, and $\left.\mathrm{NaClO}_{4}\right)$. Sorption was studied at the molecular level by surface X-ray reflectivity and was independently quantified by alpha spectrometry. For geochemical studies the use of a background electrolyte is intended to provide a constant ionic strength for the studied reaction and ideally should not interfere with the reaction in any other way. For this reason perchlorate salts, particularly sodium perchlorate $\mathrm{NaClO}_{4}$, are frequently chosen, due to the perchlorate ion's very weak coordination strength with nearly all cations. However, recent results highlight that even minor changes in the background electrolyte composition can drastically alter the reactivity of a mineral surface (Hofmann et al., 2014). In this study, trace concentrations of $\mathrm{NO}_{3}{ }^{-}$in a predominantly $\mathrm{ClO}_{4}{ }^{-}$background electrolyte significantly changed the surface morphology of calcite, which in turn affected the uptake of Eu(III) at the interface. These effects were observed even at very low nitrate concentrations (as low as $10^{-6} \mathrm{~mol} / \mathrm{L}$ ). The adsorption of Th to the muscovite basal plane from a $\mathrm{NaCl}$ solution was recently shown to be relatively simple, with a single extended outer sphere sorption complex dominating the adsorbed speciation of Th (Schmidt et al., 2012a), thus providing an ideal case for testing the influence of the background electrolyte on sorption reactions of strongly hydrated ions in the limit where only adsorption can occur without any morphological changes to the surface.

Moreover, a recent study found a potential mechanism for the surface-mediated formation of Pu(IV)-oxo-nanoparticles from an ostensibly Pu(III) solution (Schmidt et al., 2013). In this work the formation of the polymers is attributed to the presence of low concentrations of $\mathrm{Pu}(\mathrm{IV})$ in equilibrium with $\mathrm{Pu}(\mathrm{III})$. The considerably increased $\mathrm{Pu}$ concentration at the interface, it is speculated, then leads to the polymerization of those relatively minor quantities of $\mathrm{Pu}(\mathrm{IV})$. Even though the analogy of Th and $\mathrm{Pu}$ is known to be limited (Wilson, 2011), the absence of redox chemistry for Th allows to 
determine whether the polymerization reaction observed for $\mathrm{Pu}(\mathrm{III})$ is associated to $\mathrm{Pu}$ redox reactions, or specific to tetravalent actinides.

\section{EXPERIMENTAL DETAILS}

\subsection{Sorption experiments and uptake quantification}

Summarized in Table 1 are details of the aqueous Th speciation in both $0.1 \mathrm{M} \mathrm{NaCl}$ (Schmidt et al., 2012a) and $0.1 \mathrm{M} \mathrm{NaClO}_{4}$ background electrolyte solutions, modeled using data from the OECDNEA (Rand et al., 2008) and NAGRA/PSI thermodynamic databases (Hummel et al., 2002) with additions from other experimental data (Choppin and Jensen, 2011; Neck and Kim, 2001; Walther et al., 2008). The Calculations were performed using the PHREEQC solution modeling suite (version 2.17, (Parkhurst and Appelo, 1999)) and are representative of the speciation of Th in the bulk solution.

The calculated Th speciation is similar in both solutions. The most apparent difference is the lack of $\mathrm{Th}_{-} \mathrm{ClO}_{4}{ }^{-}$complexes in $\mathrm{NaClO}_{4}$ compared to a significant fraction of mono-chloro-complex $(30.7 \%)$ in $\mathrm{NaCl}$. To our knowledge, no complexation has been reported between $\mathrm{Th}$ and $\mathrm{ClO}_{4}^{-}$. The absence of Th- $\mathrm{ClO}_{4}{ }^{-}$complex data leads to an increase of the concentrations of not only the Th aquo ion $(14 \% \rightarrow$ $22 \%)$ but also the hydrolyzed species $\mathrm{ThOH}^{3+}(44 \% \rightarrow 63 \%)$ and $\mathrm{Th}(\mathrm{OH})_{2}{ }^{2+}(3.5 \% \rightarrow 6.8 \%)$. A parallel increase in the formation of the dimer complex, $\mathrm{Th}_{2}(\mathrm{OH})_{5}{ }^{3+}$, is observed $(0.19 \% \rightarrow 0.34 \%)$. It remains a minor species in the system, and all other oligomers contribute even less to the speciation under the condition. Note, that the existence of a $\mathrm{ThCl}^{3+}$ complex is suggested based on thermodynamic calculations (Schmidt et al., 2012a) using the most recent update of the NEA thermodynamic database (Rand et al., 2008) but its existence in solution could not be verified spectroscopically (Rothe et al., 2002). If no chloro-complexation occurs in the $\mathrm{NaCl}$ system, a Th speciation identical to the speciation described for $\mathrm{NaClO}_{4}$ in Table 1 would be expected. No change in speciation is expected with the different cations $\left(\mathrm{Li}^{+}, \mathrm{Na}^{+}, \mathrm{K}^{+}\right)$based on thermodynamic data, and calculations for all perchlorate media yield identical results. For both $\mathrm{NaCl}$ and $\mathrm{NaClO}_{4}$ systems, the average charge of all Th species in the bulk solution $(+2.70$ and +2.75 , respectively) is lower than the nominal +4 charge. 
Table 1. Calculated solution speciations. $[\mathrm{Th}]_{\mathrm{tot}}=1.0 \times 10^{-4} \mathrm{~mol} / \mathrm{L}, \mathrm{pH}=3.2,1 \times 10^{-1} \mathrm{~mol} / \mathrm{L} \mathrm{NaCl}$ (left) and $1 \times 10^{-1} \mathrm{~mol} / \mathrm{L} \mathrm{NaClO}_{4}$ (right).

\begin{tabular}{l|ll|l|ll}
\hline $\begin{array}{l}\text { Species } \\
(0.1 \mathrm{M} \mathrm{NaCl})\end{array}$ & $\begin{array}{l}\text { Conc. } \\
{[\mathrm{mol} / \mathrm{L}]}\end{array}$ & $\%$ & $\begin{array}{l}\text { Species } \\
\left(0.1 \mathrm{M} \mathrm{NaClO}_{4}\right)\end{array}$ & $\begin{array}{l}\text { Conc. } \\
{[\mathrm{mol} / \mathrm{L}]}\end{array}$ & $\%$ \\
\hline $\mathrm{ThOH}^{3+}$ & $4.4 \times 10^{-5}$ & 43.6 & $\mathrm{ThOH}^{3+}$ & $6.3 \times 10^{-5}$ & 62.8 \\
$\mathrm{ThCl}^{3+}$ & $3.1 \times 10^{-5}$ & 30.7 & $\mathrm{Th}^{4+}$ & $2.2 \times 10^{-5}$ & 21.7 \\
$\mathrm{Th}^{4+}$ & $1.4 \times 10^{-5}$ & 13.9 & {$\left[\mathrm{Th}\left(\mathrm{CO}_{3}\right)_{2}(\mathrm{OH})_{2}\right]^{2-}$} & $8.0 \times 10^{-6}$ & 8.0 \\
{$\left[\mathrm{Th}\left(\mathrm{CO}_{3}\right)_{2}(\mathrm{OH})\right]_{2}^{2-}$} & $8.0 \times 10^{-6}$ & 8.0 & $\mathrm{Th}(\mathrm{OH})_{2}{ }^{2+}$ & $6.8 \times 10^{-6}$ & 6.8 \\
$\mathrm{Th}(\mathrm{OH})_{2}{ }^{2+}$ & $3.5 \times 10^{-6}$ & 3.5 & $\mathrm{Th}_{2}(\mathrm{OH})_{3}{ }^{5+}$ & $3.4 \times 10^{-7}$ & 0.3 \\
\hline
\end{tabular}

The coverages of ${ }^{232} \mathrm{Th}$ sorbed on the muscovite (001) basal plane from $\mathrm{NaClO}_{4}$ and $\mathrm{LiClO}_{4}$ media were measured using alpha spectrometry (Schmidt et al., 2012a; Wilson et al., 2010) Samples were reacted with the Th solution overnight, quickly rinsed, first with a solution of the background electrolyte (to remove excess, non-sorbed Th), and subsequently with deionized water (DIW) (to remove excess background electrolyte, which would precipitate upon drying), and left to dry in air. This washing procedure can remove weakly-adsorbed species (Lee et al., 2013a; Lee et al., 2013b), and therefore the adsorbed cation coverage measured by this ex situ alpha spectrometry can be smaller than that measured by in situ RAXR (see 2.5).

Signals were collected from an area of $79 \mathrm{~mm}^{2}$ defined by the aperture $(\varnothing=10 \mathrm{~mm})$ in the stainless steel mask with $31.2 \%$ of the instrumental efficiency. All experiments were performed using ${ }^{232} \mathrm{Th}$. Due to its relatively low activity (i.e., with a half-life of $1.41 \times 10^{10} \mathrm{y}$ ), data were measured typically at very low count rate compared to those measured using more highly-active isotopes. For example, a surface coverage of $10^{-10} \mathrm{~mol} / \mathrm{cm}^{2}{ }^{232} \mathrm{Th}$, or $0.36 \mathrm{Th} / \mathrm{A}_{\mathrm{UC}}$, results in a signal of $\sim 11.4 \pm 3.4$ counts with a counting time of $108 \mathrm{~h}(388,800 \mathrm{~s})$. Therefore, the ${ }^{232} \mathrm{Th}$ coverage measured by alpha spectrometry serves mainly as a qualitative indicator of whether Th sorption occurs. 


\subsection{Muscovite substrates}

Muscovite $\mathrm{KAl}_{2}\left(\mathrm{AlSi}_{3} \mathrm{O}_{10}\right)(\mathrm{OH}, \mathrm{F})_{2}$ is a phyllosilicate with a tetrahedral-octahedral-tetrahedral (TOT) layer structure, which is also a common building block of many clay minerals. Each TOT layer in muscovite has a structural negative charge of $1 \mathrm{e}^{-}$per area of the unit cell, $\mathrm{A}_{\mathrm{UC}}=46.72 \AA^{2}$, corresponding to $0.021 \mathrm{e}^{-} / \AA^{2}$. The $\mathrm{K}^{+}$ions, which are located between the TOT layers and compensate the layer charge in the bulk crystal, are exposed upon cleavage of the muscovite lattice and removed when the cleaved surface is immersed in water (Israelachvili and Wennerstrom, 1996; Pashley, 1981, 1982).

V1 quality muscovite crystals (clear, hard, of uniform color, nearly flat, free of all stains, foreign inclusion, cracks, and other similar defects, $12.7 \times 12.7 \times 0.2 \mathrm{~mm}^{3}$ ) from the Asheville-Schoonmaker Mica Company were used for all but one experiment. For the $\mathrm{Th}-\mathrm{ClClO}_{4}$ experiment (see below) thicker crystals had to be used for practical considerations. For this purpose round V1-quality mica crystals $(\varnothing=10 \mathrm{~mm})$ with a thickness of $2 \mathrm{~mm}$ were obtained from Electron Microscopy Sciences. In all cases, the (001) basal plane is nearly atomically flat and the geometrical crystal surface can be considered identical to the reactive surface, i.e. $161 \mathrm{~mm}^{2}$, or $79 \mathrm{~mm}^{2}$, respectively. The lattice spacing perpendicular to the (001) plane was found to be within the range of $19.97 \pm 0.02 \AA$ for the samples similar to the value from the literature $(19.956 \pm 0.003 \AA$ ) (Schlegel et al., 2006). Errors for the lattice parameters of individual samples are significantly smaller.

No significant interfacial roughness was observed by X-ray reflectivity, which is typical for muscovite in aqueous conditions (Cheng et al., 2001; Fenter et al., 2010; Lee et al., 2007; Schlegel et al., 2006). Dissolution of the muscovite substrate is expected to be negligible for the experiments (Lee et al., 2010; Lee et al., 2009). Based on the dissolution rates published by Oelkers and coworkers (Oelkers et al., 2008) the expected release of $\mathrm{Al}^{3+}$ from a $12.7 \times 12.7 \mathrm{~mm}^{2}$ sample at $\mathrm{pH}=3.2$ over $2 \mathrm{~h}$ will be below $10^{-11}$ moles. According to these calculations less than 0.001 monolayers of the substrate will dissolve within the duration of the experiment, in good agreement with the lack of observable interfacial roughness. 


\subsection{X-Ray reflectivity experiments}

To probe the influence of both anions and cations on the sorption behavior of the non-redoxactive actinide, and to isolate trends in the observed effects, four background electrolyte media were tested: $\mathrm{NaClO}_{4}$ at two different concentrations, $\mathrm{LiClO}_{4}$, and $\mathrm{KClO}_{4}$. In addition, an experiment was conducted in which a $\mathrm{NaCl}$ solution was replaced by $\mathrm{NaClO}_{4}$ after sorption had occurred. The samples and their respective solution conditions are listed in

Table 2.

Table 2. Details for the experimental solution conditions for all samples discussed in this work

\begin{tabular}{l|llll}
\hline Designation & Electrolyte & I & pH & c(Th(IV)) \\
\hline $\mathrm{Th}_{-} \mathrm{NaCl}^{\mathrm{a}}$ & $\mathrm{NaCl}$ & $0.1 \mathrm{M}$ & 3.2 & $0.1 \mathrm{mM}$ \\
$\mathrm{Th}_{-} \mathrm{hiNaClO}_{4}$ & $\mathrm{NaClO}_{4}$ & $0.1 \mathrm{M}$ & 3.2 & $0.1 \mathrm{mM}$ \\
$\mathrm{Th}_{-} \mathrm{loNaClO}_{4}$ & $\mathrm{NaClO}_{4}$ & $0.01 \mathrm{M}$ & 3.2 & $0.1 \mathrm{mM}$ \\
$\mathrm{Th}_{-} \mathrm{ClClO}_{4}$ & $\mathrm{NaCl} / \mathrm{NaClO}_{4}$ & $0.1 \mathrm{M}$ & 3.2 & $0.1 \mathrm{mM}$ \\
$\mathrm{Th}_{-} \mathrm{LiClO}_{4}$ & $\mathrm{LiClO}_{4}$ & $0.1 \mathrm{M}$ & 3.5 & $0.1 \mathrm{mM}$ \\
$\mathrm{Th}^{-} \mathrm{KClO}_{4}$ & $\mathrm{KClO}_{4}$ & $0.1 \mathrm{M}$ & 3.5 & $0.1 \mathrm{mM}$ \\
\hline
\end{tabular}

${ }^{a}$ From (Schmidt et al., 2012a)

The sample preparation procedure was identical for all samples except the exchange experiment Th- $\mathrm{ClClO}_{4}$. Solutions were prepared from ${ }^{232} \mathrm{Th}$ stock solutions (in $\mathrm{HNO}_{3}$ ) by appropriate dilution with the respective background electrolyte. No $\mathrm{pH}$ adjustments were performed to avoid inducing local changes in Th chemistry, e.g. leading to oligomerization or precipitation. Consequently, pH values vary slightly throughout the series.

Freshly cleaved mica crystals were suspended in the Th solution overnight for the sorption reactions. Afterwards the crystals were removed from the solution, quickly mounted in a thin-film cell for X-ray reflectivity measurements, and covered with $20 \mu 1$ of the reaction solution. The liquid film was then enclosed with a $7.5 \mu$ m-thick Kapton ${ }^{\circledR}$ film and the cell was closed with two additional Kapton ${ }^{\circledR}$ domes for containment. This setup has been described in more detail previously(Schmidt et al., 2012b). For the exchange experiment with sample $\mathrm{ThClClO}_{4}$ the sorption reaction was performed in $\mathrm{NaCl}$ background media under the same conditions as described above. We use a second, previously described cell for X-ray scattering experiments with radioactive samples (Schmidt et al., 
2011) to change the background electrolyte online. The sample was mounted in the cell's sample compartment, and covered with the $\mathrm{NaCl}$ reaction solution. As in the other cell, the solution was enclosed using a thin Kapton ${ }^{\circledR}$ film, and radioactive containment was achieved using two domed layers of Kapton®. The liquid container of the cell was filled with a solution of equivalent $\mathrm{pH}$ and ionic strength in $\mathrm{NaClO}_{4}$, without added Th(IV), to allow the exchange of solutions during the experiment.

\section{$2.4 \quad \mathrm{X}$-ray reflectivity measurements}

The combination of crystal truncation rod (CTR) measurements and resonant anomalous X-ray reflectivity was applied to probe elemental distributions in the near-surface regime in situ, ranging in height from sub-monolayer adsorption structures to extended (few nm wide) distributions, with a high spatial resolution (i.e., <1 $\AA$ ). In particular, the RAXR technique has element specificity with reasonably good detection limit in estimating the atomic coverage at an interface (Lee et al., 2013c; Schmidt et al., 2012a). For example, ion coverages as low as $\sim 0.03$ atoms $/ \mathrm{A}_{\mathrm{UC}}$ have been measured on muscovite with an area of the unit cell of $46.72 \AA^{2}$ (Lee et al., 2010). These characteristics make surface X-ray diffraction a powerful and versatile tool for geochemical systems (Fenter, 2002; Park et al., 2006), in particular when studying complex multi-species systems (Catalano et al., 2008; Lee et al., 2010; Lee et al., 2013c; Schmidt et al., 2013). Detailed reviews on the methods can be found in the literature (Feidenhans'l, 1989; Fenter et al., 2007; Park and Fenter, 2007; Robinson and Tweet, 1992).

All X-ray reflectivity (XR) measurements were performed at the GeoSoilEnviroCARS undulator beamline 13-ID-C at the Advanced Photon Source (APS), with a beam size of $0.05-0.25 \mathrm{~mm}$ horizontally and $0.5-1.0 \mathrm{~mm}$ vertically with a typical flux of $\sim 10^{12}$ photons/s. For some experiments the beam was partly defocused and collimated by slits in order to prevent chemical changes induced by the X-ray beam. No beam induced effects were observed. Specular reflectivity data were collected by reflecting the incident beam from the sample surface and detecting the reflected beam using a Dectris PILATUS 100K 2D pixel array detector (Eikenberry et al., 2003). For CTR measurements (i.e., non-resonant XR) the incident photon energy E (typically $18 \mathrm{keV}$ ) was fixed at a value well away from the Th $\mathrm{L}_{\mathrm{III}}$ absorption edge $(16.3 \mathrm{keV})$. The reflected intensity was recorded as a function of the momentum transfer q oriented along the surface normal direction (i.e., specular reflection condition). 
RAXR data were collected by scanning the energy through a $600 \mathrm{eV}$ range centered on the $\mathrm{Th}_{\mathrm{III}}$

edge at selected values of q. System stability was verified by periodically returning to designated conditions and checking reproducibility. Two datasets (Th-hiNaClO 4 and $\mathrm{Th}-\mathrm{NaCl}$ ) were also reproduced using different crystals and at a different beamline (6-ID-B at the Advanced Photon Source).

The anomalous dispersion terms required for analyzing the RAXR data, as well as determining the exact absorption edge position of the studied Th sample under the given conditions were derived from fluorescence X-ray absorption near-edge structure (XANES) measurements collected on the same samples in grazing-incidence mode using an SII Vortex ME4 X-ray fluorescence detector and applying a difference Kramers-Kronig transform (Cross et al., 1998; Fenter et al., 2010).

\subsection{X-Ray reflectivity data analysis}

The CTR measurement defines the total interfacial electron density, including that from water and adsorbed ions. CTR data were fit by applying a parameterized structural model consisting of the ideal muscovite substrate lattice, the interfacial region, and bulk water. The interfacial region includes the structural relaxation of atoms in the two top unit-cell layers of the muscovite surface and the presence of near-surface species such as adsorbed species and water. The distribution of each adsorbed species is described as a Gaussian peak, whose structure factor is expressed as:

$$
F=\sum_{j} c_{j} f_{j}(q) \exp \left(i q z_{j}\right) \exp \left[-\frac{q^{2} u_{j}^{2}}{2}\right]
$$

where $f_{\mathrm{j}}(\mathrm{q})$ is the atomic scattering factor and $\mathrm{c}_{\mathrm{j}}, \mathrm{z}_{\mathrm{j}}$, and $\mathrm{u}_{\mathrm{j}}$ are the occupancy, height from the surface, and rms width of the $\mathrm{j}^{\text {th }}$ atom, respectively. Bulk water was expressed by a layered water-model (Cheng et al., 2001; Schlegel et al., 2006). The quality-of-fit of each model was characterized by a scaled $\chi^{2}$ and an R-factor (see Electronic Annex (EA) for details). reflectivity. Procedures for RAXR data fitting are described in detail in the literature (Fenter et al., 2007; Park and Fenter, 2007). For several samples (see below) we were limited to qualitative comparison of results, using our previous study of Th sorption on muscovite(Schmidt et al., 2012a) as 
a reference, due to the very low population of Th at the interface. Data processing of the RAXR spectra followed the procedures described earlier.

In a first step, semi-quantitative constraints on the elemental distribution were established (Fenter et al., 2007; Park and Fenter, 2007). The systematic variations in the resonant modulations' amplitude $A_{R}(q)$ and phase $\Phi_{R}(q)$ are obtained from a model-independent analysis of the RAXR spectra. The relationship between the amplitude and phase and the partial structure factor of resonant atom at the interface can be written as:

where $c_{j}, u_{j}$, and $z_{j}$ are the occupancy, rms width and average height of Th species $\mathrm{j}$, respectively. The surface loading is estimated as $\Sigma_{\mathrm{j}}\left(\mathrm{c}_{\mathrm{j}}\right)=\theta$ using the amplitude in the limit of $\mathrm{q} \rightarrow 0$, while the $\mathrm{q} \rightarrow 0$ limit for $\Phi_{\mathrm{R}}(\mathrm{q}) / \mathrm{q}$ corresponds to the average height of the elemental distribution (Park and Fenter, 2007). Additional information can be obtained from inspection of the q-dependence of the resonant amplitude and phase, such as the vertical width of the distribution and the relative heights of multiple distinct adsorption species, if any (Park and Fenter, 2007). This model-independent approach is partially limited in its accuracy by the absence of data near $q=0$, yet it is helpful in that it provides an unbiased initial constraint that can be used to build a model for the model-dependent RAXR analysis. data with a model composed of individual Gaussian peaks (Fenter et al., 2007). The resonant structure factor is expressed as

$$
F_{R}(q)=\left(f^{\prime}(E)+i f^{\prime \prime}(E)\right) \sum_{j} c_{j} \exp \left(i q z_{j}\right) \exp \left[-\frac{q^{2} u_{j}^{2}}{2}\right]
$$


273

274

275

276

277

278

279

280

281

282

283

284

285

286

287

288

\subsection{Uptake measurements}

As a first step, uptake of Th from $0.1 \mathrm{M} \mathrm{LiClO}_{4}$ and $\mathrm{NaClO}_{4}$ solution was quantified by alpha spectrometry. In the Th- $\mathrm{LiClO}_{4}$ system $\left([\mathrm{Th}]=1.0 \times 10^{-4} \mathrm{~mol} / \mathrm{L}, \mathrm{pH}=3.3 \pm 0.3,0.1 \mathrm{M} \mathrm{LiClO}_{4}{ }^{232} \mathrm{Th}\right.$ coverage was $1.6 \pm 0.3 \mathrm{Th} / \mathrm{A}_{\mathrm{UC}}\left(=0.14 \mu \mathrm{g} / \mathrm{cm}^{2}\right)$. This coverage is significantly larger than seen in 0.1 M NaCl media, 0.15 Th/ $\mathrm{A}_{\mathrm{UC}}$, using the same technique (Schmidt et al., 2012a).

Alpha spectrometry was not able to detect $\mathrm{a}^{232} \mathrm{Th}$ coverage above background (detection limit approx. $0.1 \mathrm{Th} / \mathrm{A}_{\mathrm{UC}}$ ) from the $0.1 \mathrm{M} \mathrm{NaClO}_{4}$ background electrolyte solution (Th-hiNaClO${ }_{4}$ ), in contrast to the previous results obtained from a $\mathrm{NaCl}$ solution $\left(0.15 \pm 0.02 \mathrm{Th} / \mathrm{A}_{\mathrm{UC}}\right)$ (Schmidt et al., 2012a). These measurements are constrained by the low specific activity of ${ }^{232} \mathrm{Th}$, as described in 2.1 . A better understanding of the Th sorption at the muscovite basal plane in this system can be obtained from RAXR measurements, which are not only capable of detecting lower Th concentrations at the interface, but also provide insight into its vertical distribution (i.e. its speciation) at the interface. Yet, the absence of detectable signal is in agreement with the RAXR findings (see the next section). Nevertheless, these results demonstrate the surprising sensitivity of Th uptake at the muscovite surface to the choice of electrolyte and motivated the more extensive measurements described below to understand this observation. 
a) $\mathrm{Th}-\mathrm{NaCl}$

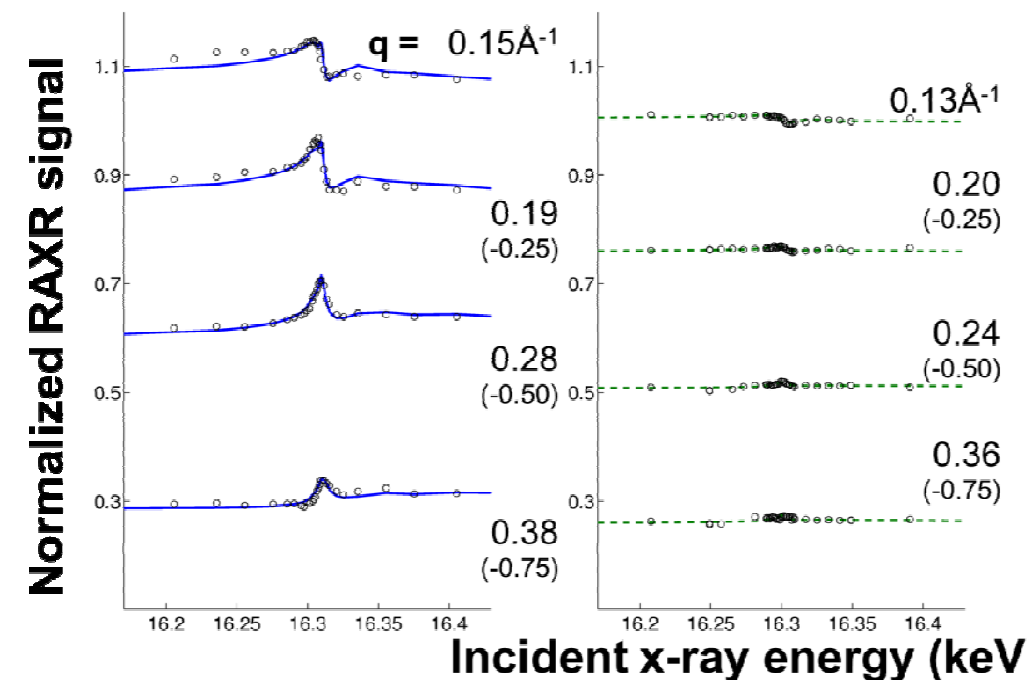

d) $\mathrm{Th}-\mathrm{hiNaClO}{ }_{4}$

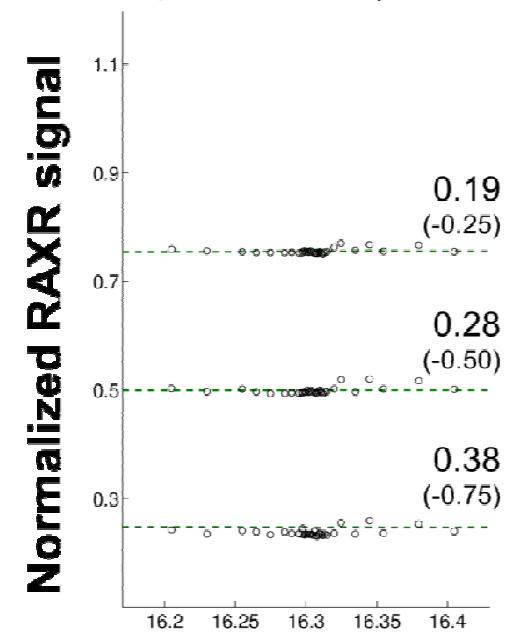

c) Th-loNaClO

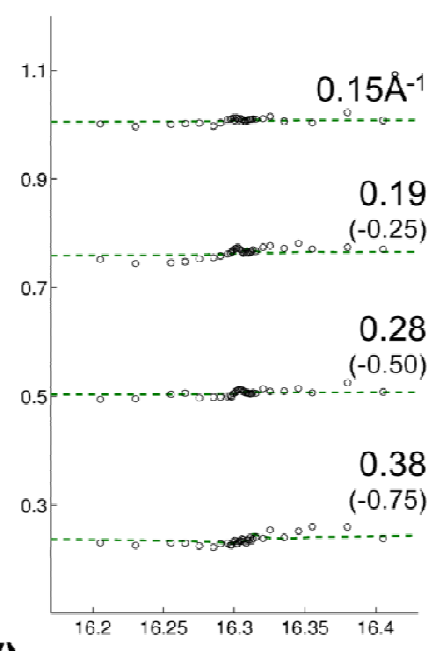

Incident x-ray energy (keV)

e) $\mathrm{Th}-\mathrm{LiClO}_{4}$

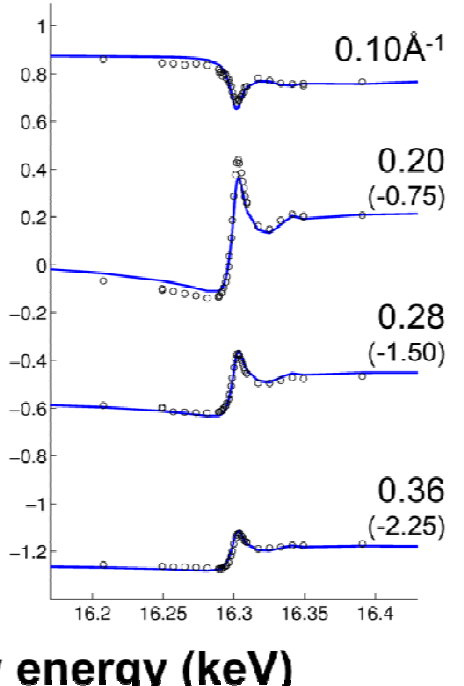

Figure 1. Selected resonant anomalous X-ray reflectivity data (black circles) measured from the muscovite (001) surface for the samples in Table 2. Each spectrum represents the variation of the specular reflectivity measured as a function of photon energy, $\mathrm{E}$, at a different fixed momentum transfer, $\mathrm{q}\left(\AA^{-1}\right)$, as indicated. Spectra are normalized to the non-resonant structure factor $\mathrm{F}_{\mathrm{NR}}$ as $\left(\left|\mathrm{F}_{\text {tot }}(\mathrm{q}, \mathrm{E})\right|^{2} /\left|\mathrm{F}_{\mathrm{NR}}(\mathrm{q})\right|^{2}\right)$, where $\mathrm{F}_{\mathrm{tot}}$ and $\mathrm{F}_{\mathrm{NR}}$ are total and non-resonant structure factors, respectively, and offset vertically for clarity (offset given in brackets for each spectrum). The blue lines show the calculated intensities from the best-fit models, where applicable. The green dashed lines are results from model-independent analysis and may serve as a guide-to-the-eye. Note that the y-axis scale for Th- $\mathrm{LiClO}_{4}$ (e) is about twice larger than the others.

The RAXR data measured in various electrolyte conditions (Figure 1) are visually different from one another, indicating that the thorium-muscovite interaction is influenced by the choice of electrolyte. Small modulations are observed for $\mathrm{Th}-\mathrm{KClO}_{4}$ and $\mathrm{Th}-\mathrm{loNaClO}_{4}$ whereas no discernible 
modulations are observed for Th-hiNaClO 4 . In contrast, the RAXR spectra of Th- $\mathrm{LiClO}_{4}$ show significantly larger modulations than those of the other systems (note the difference in y-axis scale for Th- $\mathrm{LiClO}_{4}$ from the others in Fig. 1) that are substantially larger than those observed in the Th-NaCl reference system. The data in this reference system were fit with a partially-overlapping two-peak model describing a broadly distributed extended outer sphere sorption species of Th (Schmidt et al., 2012a). Since the fractional modulation observed in the RAXR spectra are proportional to the adsorbed Th coverage, these data immediately indicate that Th adsorption on muscovite is a strong function of the choice of electrolyte, consistent with the alpha spectrometry measurements.

The total coverages of Th at the muscovite-water interface were estimated using the modelindependent RAXR analysis (Park and Fenter, 2007). A complete lack of modulations for ThhiNaClO ${ }_{4}$ indicates that there is no significant coverage of the resonant atom registered at the reflecting interface, $\theta\left(\mathrm{Th}-\mathrm{hiNaClO} \mathrm{N}_{4}\right) \cong 0$. At $0.01 \mathrm{M} \mathrm{NaClO}_{4}$ concentration, small modulations are visible for data at $\mathrm{q}=0.19$ and $0.28 \AA^{-1}$. The estimated Th coverage, $\theta\left(\mathrm{Th}-\mathrm{loNaClO}{ }_{4}\right) \sim 0.04 \mathrm{Th} / \mathrm{A}_{\mathrm{UC}}$, is ten times smaller than that from $\mathrm{NaCl}$ media (Schmidt et al., 2012a). Th- $\mathrm{KClO}_{4}$ shows similar behavior with modulations that are significantly weaker than those observed in $\mathrm{NaCl}$, with $\theta\left(\mathrm{Th}-\mathrm{KClO}_{4}\right) \sim 0.07 \mathrm{Th} / \mathrm{A}_{\mathrm{UC}}$. By comparison, the Th coverage for Th- $\mathrm{LiClO}_{4}, \theta\left(\mathrm{Th}-\mathrm{LiClO}_{4}\right) \sim 5$

\subsubsection{Structural model $\mathrm{Th}^{-\mathrm{LiClO}_{4}}$}

The RAXR data collected in $0.1 \mathrm{M} \mathrm{LiClO}_{4}$ were analyzed using a model-dependent approach to obtain the vertical distribution of Th species sorbed at the interface. The same type of full structural analysis was not possible for the other $\mathrm{ClO}_{4}{ }^{-}$systems because the observed RAXR signals were too weak.

The best fit structural model for the Th- $-\mathrm{CiClO}_{4} \mathrm{RAXR}$ is presented in Figure 2. This includes both the total electron density profile (black line) and the Th-specific electron density (blue). The Thspecific electron density distribution in $0.1 \mathrm{M} \mathrm{NaCl}$ (Schmidt et al., 2012a) is shown in a black dotted

328 line for comparison. The Th distribution in $\mathrm{Th}-\mathrm{LiClO}_{4}$ consists of two broad layers at $\sim 4.1 \AA$ and $329 \sim 29 \AA$, respectively, indicating the coexistence of two Th sorption modes. The derived Th distribution 
model has fairly small statistical uncertainty (i.e., $1 \sigma$ errors are indicated as an orange band in Figure 2 ), and reproduces the experimental data (RAXR quality-of-fit: $\chi^{2}=5.1, \mathrm{R}=3.8 \%$ ). The first Th layer is closer to the surface than the extended outer sphere complex observed for Th- $\mathrm{NaCl}$ (Schmidt et al., 2012a). It covers the range of adsorption heights typically occupied by sorption complexes of hydrated and partly hydrated cations (Lee et al., 2010). The second peak is broader and reaches up to $50 \AA$ height from the surface. This distribution is similar to what has been observed upon adsorption (Schmidt et al., 2012b) and formation (Schmidt et al., 2013) of Pu nanoparticles on the muscovitewater interface, but the coverage of $\mathrm{Th}$ is smaller than those of $\mathrm{Pu}$ in the adsorbed nanoparticles (4.9 $\mathrm{Th} / \mathrm{A}_{\mathrm{UC}}$ compared to 9.9 and $10.8 \mathrm{Pu} / \mathrm{A}_{\mathrm{UC}}$, respectively).

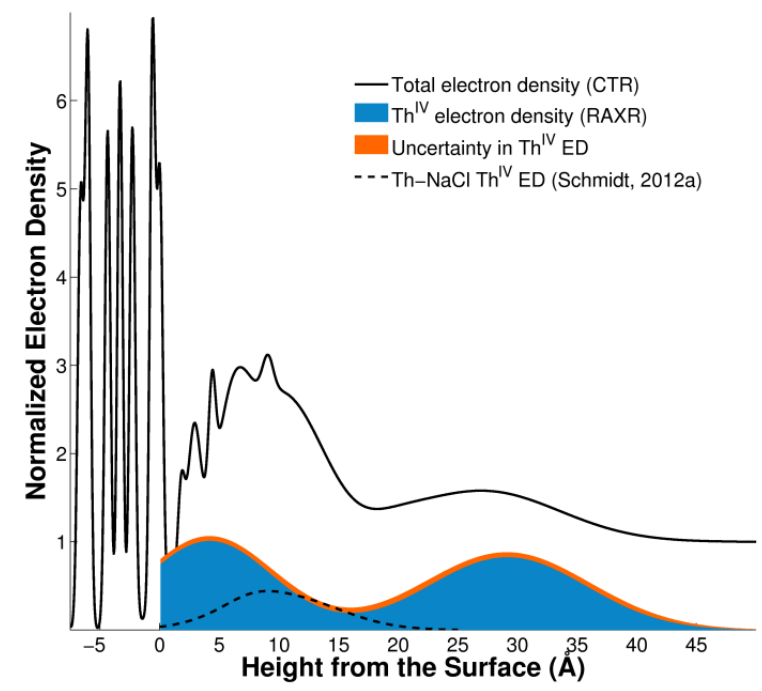

Figure 2. Interfacial structure of Th- $\mathrm{LiClO}_{4}$. Total electron density (ED) profile derived from CTR (solid black line) and Th electron density distribution derived from RAXR (blue area, uncertainty in electron density is shown in orange). The Th-specific ED profile measured for Th- $\mathrm{NaCl}$ (Schmidt et al., 2012a) is also plotted (dashed black line) for comparison. The electron density is normalized by that of bulk water $\rho$ (bulk water) $=0.33 \mathrm{e}^{-} / \AA^{3}$. The average height of muscovite surface oxygens is set to be $\mathrm{z}=0 \AA$.

\subsection{Crystal truncation rods}

To understand the immense differences in the sorption behavior of Th, we have to take into consideration how the background electrolyte changes the conditions at the muscovite (001) basal plane. The CTR data and total electron density profiles for all background electrolytes are shown in 


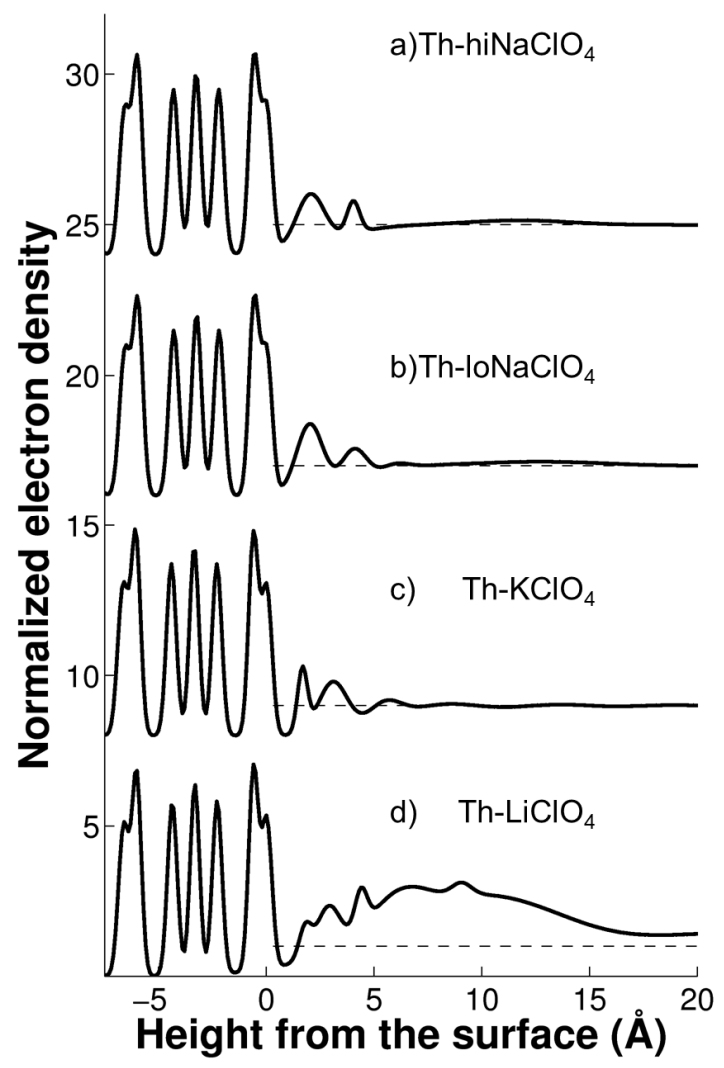
distance from the surface, for $\mathrm{Th}-\mathrm{KClO}_{4}$ they are shifted towards smaller distances from the interface at 1.7 and 3.1 $\AA$, with one additional peak at 5.7 $\AA$. Both Th- $-\mathrm{oNaClO}_{4}$ and Th-hiNaClO 4 show a weak broad feature in their respective ED distributions, centered at 12.7 and $11.7 \AA$, with the ED approaching the value of bulk water at $\sim 20 \AA$. In both cases the broad peak contributes little to the total $\mathrm{ED}, \sim 7 \%$ above bulk water $\mathrm{ED}$ for $\mathrm{Th}-\mathrm{loNaClO}_{4}$ and $\sim 6 \%$ for $\mathrm{Th}-\mathrm{hiNaClO}$. The coverage of adsorbed species is larger for Th-loNaClO 4 than for Th-hiNaClO in the RAXR spectra. 
The electron densities observed near the muscovite surface are generally similar to that identified previously for muscovite in electrolyte solutions of simple ions, with two layers that are observed close to the interface. The structural details are, however, different: The adsorbed water appears closer to the interface at $1.3 \AA$ and $2.5 \AA$ (Cheng et al., 2001), compared to $2.0 \AA$ and $4.0 \AA$ in $\mathrm{NaClO}_{4}$ samples and $1.7 \AA$ and $3.1 \AA$ for Th- $\mathrm{KClO}_{4}$. The peak positions are also different upon sorption of $\mathrm{Na}^{+}$ in the absence of $\mathrm{Th}(\mathrm{IV})$, where the first adsorbed layer was found at $1.2 \AA$ and $2.4 \AA$ with a third species at $5.2 \AA$ for $\mathrm{Na}^{+}$. The electron density profile for $\mathrm{Th}-\mathrm{KClO}_{4}$ is similar to the one found for $\mathrm{K}^{+}$ adsorption in the absence of Th (Fig. 4), yet the structural details vary. For $\mathrm{K}^{+}$in the absence of Th, layers at $1.9 \AA$, $3.3 \AA$, and $5.4 \AA$ have been reported (Lee et al., 2012). The positions of the peaks are reasonably close to each other, but the peak intensities are consistently larger in the presence of Th(IV). This is consistent with co-adsorption of $\mathrm{K}^{+}$with small quantities of Th, as indicated by the RAXR results presented here.

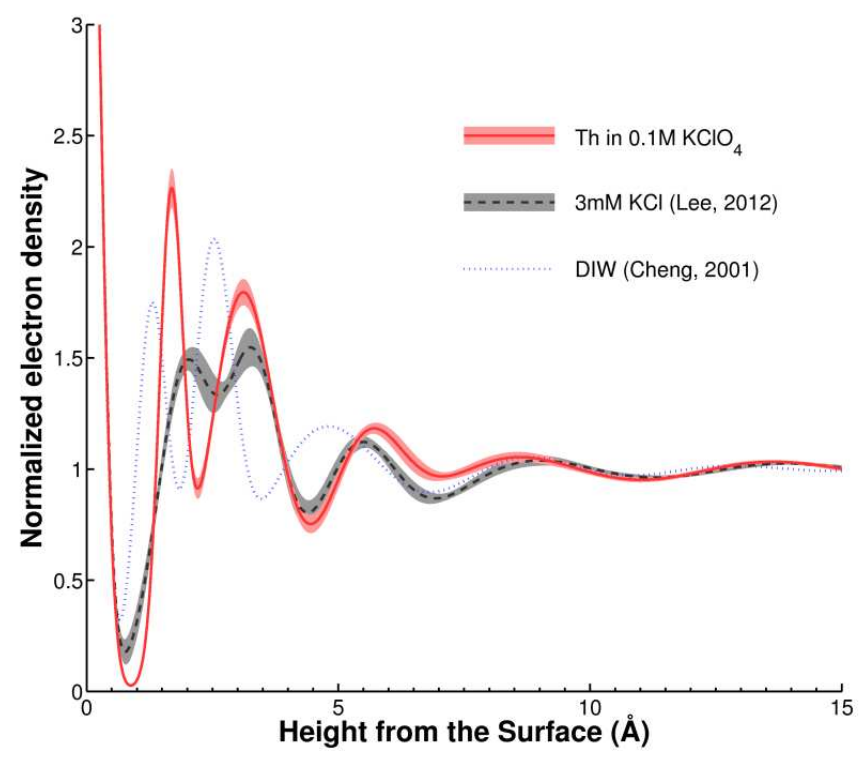

Figure 4. Total electron density derived from CTR for $\mathrm{K}^{+}$samples. Electron density (ED) is normalized by that of bulk water $\rho($ bulk water $)=0.33 \mathrm{e} / \AA^{3}$. Electron density profiles for Th- $\mathrm{KClO}_{4}$ (red line, this work), muscovite in $3 \mathrm{mM} \mathrm{KCl}$ (black dashed line, (Lee et al., 2012)), and muscovite in deionized water (dotted blue line, (Cheng et al., 2001)) are shown. Uncertainties in the ED profiles for Th- $\mathrm{KClO}_{4}$ (light red area) and $3 \mathrm{mM} \mathrm{KCl}$ on muscovite (grey area) are shown as well.

The total electron density profile derived from the CTR data for Th- $\mathrm{LiClO}_{4}$ is plotted in Figure $2 \mathrm{~d}$ (solid black line). The structure differs substantially from the profiles discussed in the previous 
386

paragraphs. It includes several sharp features overlapped with an intense broad peak within $\sim 15 \AA$ from the surface. These are followed by a broad structured peak centered at $\sim 27 \AA$, which slowly declines to the electron density of bulk water at a distance of $50 \AA$ from the interface. That is, a primary difference between these data with respect to the others is the presence of a significant enhancement of the electron density near the interface, with a magnitude of the density that can only be explained by the adsorption of large amounts of Th.

\subsection{Exchange experiments $\mathrm{NaCl} / \mathrm{NaClO}_{4}$}
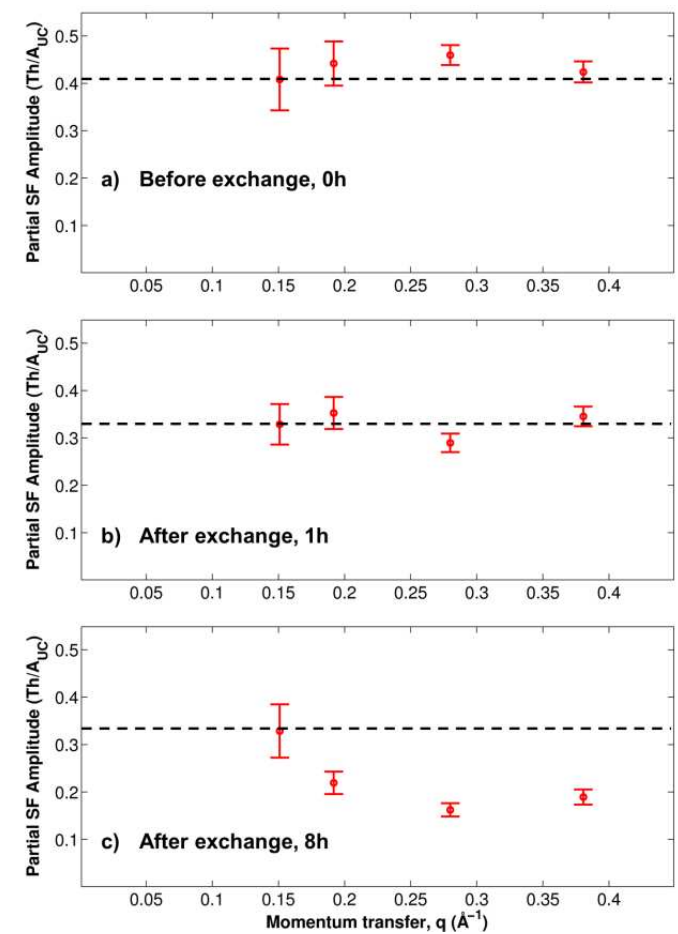

Figure 5. Amplitude of the element-specific partial structure factors of Th(IV) adsorbed at muscovite (001)-aqueous solution interface determined by model-independent (data points) analyses of RAXR spectra for the samples of the $\mathrm{NaClO}_{4} / \mathrm{NaCl}$ exchange experiment: a) after adsorption of $\mathrm{Th}$ from $\mathrm{NaCl}$, b) $1 \mathrm{~h}$ after replacing $\mathrm{NaCl}$ by $\mathrm{NaClO}_{4}$, c) $8 \mathrm{~h}$ after replacing $\mathrm{NaCl}$ by $\mathrm{NaClO}_{4}$. Dashed lines are guides-to-the-eye, and may facilitate extrapolation to $\mathrm{q} \rightarrow 0 \AA^{-1}$.

The reversibility of the effect of sodium perchlorate on Th(IV)'s sorption behavior was tested by comparing selected RAXR scans after Th(IV) adsorption from $0.1 \mathrm{M} \mathrm{NaCl}$ media, with those from the same sample after one and eight hours in $0.1 \mathrm{M} \mathrm{NaClO}_{4}$. The scans are shown in the $\mathrm{EA}$ in comparison to the low-q RAXR spectra measured in $\mathrm{NaCl}$ medium (Figure S4). The spectra measured before exchanging the background electrolyte are similar to the previously reported spectra measured under the same condition (Schmidt et al., 2012a), confirming their reproducibility. The coverage estimated 
from the amplitude of the RAXR spectra by model-independent analysis (Figure 5) matches the

406 coverage found previously for Th adsorption from $\mathrm{NaCl}$ media, i.e. $\theta(\mathrm{Th})=0.4 \mathrm{Th} / \mathrm{A}_{\mathrm{UC}}(\mathrm{Schmidt}$ et

407 al., 2012a). of $0.1 \mathrm{M} \mathrm{NaClO}_{4}$ solution without added Th and left to react for eight hours. After one hour of reaction we observed $\sim 30 \%$ decreases in the RAXR signal amplitude at $q=0.15-0.38 \AA^{-1}$ (Figure 5). The reduction of amplitude indicates partial removal of sorbed Th from an initial coverage of $0.4 \mathrm{Th} / \mathrm{A}_{\mathrm{UC}}$ to approximately $0.33 \mathrm{Th} / \mathrm{A}_{\mathrm{UC}}$. There is no change in the q-dependent variation of the resonant amplitude, suggesting that the distribution remained unchanged. Eight hours after flushing with

$414 \mathrm{NaClO}_{4}$ solution the spectra show that the resonant amplitude at the lowest q value was unchanged, but that the amplitude decreases with increasing q. This suggests that while the coverage has not changed significantly, the speciation has changed, likely to a broader, less organized Th distribution.

417 The desorption process is slow, and it was not possible to achieve complete removal of Th(IV) within the time allotted for the experiment $(\sim 10 \mathrm{~h})$.

In the previous $\mathrm{Th}-\mathrm{NaCl}$ study (Schmidt et al., 2012a) quick removal of about $60 \%$ of $\mathrm{Th}$ had been found by comparison of the Th coverage obtained in situ by RAXR $\left(0.4 \mathrm{Th} / \mathrm{A}_{\mathrm{UC}}\right)$ and after 421 flushing with $\mathrm{NaCl}$ solution and deionized water by alpha spectrometry $\left(0.15 \mathrm{Th} / \mathrm{A}_{\mathrm{UC}}\right)$. Consequently, $42230 \%$ removal over eight hours in $\mathrm{NaClO}_{4}$ would suggest that desorption is actually slower in $\mathrm{NaClO}_{4}$ than in $\mathrm{NaCl}$, although it should be cautioned that the experiments are not entirely comparable.

\section{DISCUSSION}

425

\subsection{Anion effect}

The present data offer insight into background electrolyte effects on the sorption behavior of tetravalent Th on the muscovite (001) basal plane at slightly acidic solution $\mathrm{pH}(3.3 \pm 0.3)$. The reference point for this discussion will be the previously observed behavior of Th adsorption from $0.1 \mathrm{M} \mathrm{NaCl}$ solution, which leads to the formation of an extended outer sphere sorption complex of 
$430 \mathrm{Th}(\mathrm{IV})$, with a coverage $\theta(\mathrm{Th})=0.4 \mathrm{Th} / \mathrm{A}_{\mathrm{UC}}$ (Schmidt et al., 2012a). This sorption structure is distinct 431 from that observed in the other studied electrolytes.

432 The most unexpected differences in thorium's reactivity with respect to muscovite in $0.1 \mathrm{M} \mathrm{NaCl}$ 433 are observed in $0.1 \mathrm{M} \mathrm{NaClO}_{4}\left(\mathrm{Th}-\mathrm{hiNaClO}{ }_{4}\right)$. Through this relatively simple change in anion of the 434 background electrolyte, the sorption of Th(IV) to muscovite is effectively inhibited. Note that the 435 duplicate measurements of these two experiments as mentioned in Section 2.4 yielded the same results 436 (data not shown). The total ED profile obtained from CTR shows that Th and/or perchlorate still affect 437 the interfacial structure. The adsorbed water structure is clearly different from the structure found upon 438 adsorption of $\mathrm{Na}^{+}$from $\mathrm{NaCl}$ solution in the absence of $\mathrm{Th}(\mathrm{IV})$ (Lee et al., 2012) with peaks shifted to 439 larger distances from the interface. In addition, a broad feature at a distance close to the sorption 440 height of the The extended outer sphere complex $(11.7 \AA$ compared to $10.1 \AA)$ is found. The peak is 441 however very weak, and if it is related to Th adsorption the amount of adsorbed Th is diminutive (The 442 peak contributes electron density equivalent to $\sim 0.3 \mathrm{H}_{2} \mathrm{O} / \mathrm{A}_{\mathrm{UC}}$, or $\sim 0.06 \mathrm{Th} / \mathrm{A}_{\mathrm{UC}}$ if all electron density 443 originates from Th). The effect is observed to a lesser extent at lower ionic strength of $\mathrm{NaClO}_{4}$ 444 (Th-loNaClO $\left.{ }_{4} ; \mathrm{I}=0.01 \mathrm{M}\right)$. RAXR modulations were detected, proving that a small amount of Th has 445 adsorbed at the interface, but the coverage is nearly ten times lower $\left(\theta(\mathrm{Th}) \sim 0.04 \mathrm{Th} / \mathrm{A}_{\mathrm{UC}}\right)$ than for 446 Th-NaCl. A model-independent analysis (see EA) implies a broad distribution of Th(IV) at the 447 interface with a very low coverage.

448 Table 3 . Thorium coverages $\theta$, measured by RAXR.

\begin{tabular}{l|lccc|l}
\hline Sample & $\mathrm{Th}^{-\mathrm{LiClO}_{4}}$ & $\mathrm{Th}-\mathrm{KClO}_{4}$ & $\mathrm{Th}-\mathrm{loNaClO}_{4}$ & Th-hiNaClO \\
& & $\mathrm{Th}-\mathrm{NaCl}$ \\
$\theta\left(\mathrm{Th} / \mathrm{A}_{\mathrm{UC}}\right)$ & 4.9 & $\sim 0.07$ & $<0.04$ & n.d. & 0.4 \\
\hline Sample & Exch. Exp. (0h) & Exch. Exp. (1h) & Exch. Exp. (8h) & \\
$\theta\left(\mathrm{Th} / \mathrm{A}_{\mathrm{UC}}\right)$ & $\sim 0.4$ & $\sim 0.33$ & & $\sim 0.33$ & \\
\hline
\end{tabular}

\subsection{Cation effect}

Our results show that the choice of cation introduced with the background electrolyte has a significant effect on the Th(IV) sorption as well. A very similar Th coverage is found in $0.1 \mathrm{M} \mathrm{KClO}_{4}$ $\left(\mathrm{Th}-\mathrm{KClO}_{4}\right)$ compared to $0.01 \mathrm{M} \quad \mathrm{NaClO}_{4} \quad\left(\mathrm{Th}-\mathrm{loNaClO}_{4}\right)$. For $\mathrm{Th}-\mathrm{KClO}_{4}$ the coverage is $454 \sim 0.07 \mathrm{Th} / \mathrm{A}_{\mathrm{UC}}$, meaning that sorption is still about five times weaker than from $\mathrm{NaCl}$ solution. 
However, this indicates that $\mathrm{K}^{+}$has a positive effect on the adsorption of Th relative to $\mathrm{Na}^{+}$in $\mathrm{ClO}_{4}{ }^{-}$ media, where under otherwise identical solution composition (Th-hiNaClO 4 ) no significant $\mathrm{Th}$ sorption was observed.

A substantial change in Th reactivity also is observed upon adsorption from $\mathrm{LiClO}_{4}$ background (Th-LiClO$)_{4}$ ). Here, uptake (i.e., $\theta(\mathrm{Th})=4.9 \mathrm{Th} / \mathrm{A}_{\mathrm{UC}}$ in $\left.0.1 \mathrm{M} \mathrm{LiClO}{ }_{4}\right)$ is increased markedly beyond the observed uptake from $\mathrm{NaCl}$ media $\left(0.4 \mathrm{Th} / \mathrm{A}_{\mathrm{UC}}\right.$ in $\left.0.1 \mathrm{M} \mathrm{NaCl}\right)$. In this system, there appears to be no inhibitory effect from the presence of perchlorate on Th uptake to the muscovite surface in contrast to those in $\mathrm{NaClO}_{4}$ and $\mathrm{KClO}_{4}$ systems. The observed $\mathrm{Th}(\mathrm{IV})$ structure consists of two broad distributions, which can be interpreted as Th in adsorbed Th-nanoparticles and larger aggregates of Th-nanoparticles. The presence of Th(IV) sorption complexes as minor species cannot be ruled out. $\mathrm{Pu}(\mathrm{IV})$-oxo-nanoparticles have been shown to form at the muscovite basal plane from $\mathrm{Pu}(\mathrm{III})$ solutions under similar conditions (Schmidt et al., 2013). Finding a similar mode of nanoparticle formation from Th(IV) solutions suggests that the same mechanism is applicable for tetravalent actinides independent of previous redox reactions. We can assume that the interfacial concentration of $\mathrm{Th}(\mathrm{IV})$ is larger in this experiment than the concentration of $\mathrm{Pu}(\mathrm{IV})$, which was only a minor species in the previous experiments (Schmidt et al., 2013). However, the observed Th coverage is lower than the Pu coverage (4.9 $\mathrm{Th} / \mathrm{A}_{\mathrm{UC}}$ compared to $\left.9.9 \mathrm{Pu} / \mathrm{A}_{\mathrm{UC}}\right)$ and the extent of the Th distribution is smaller $\left(\mathrm{z}_{\max }(\mathrm{Th})<50 \AA\right.$; $\left.\mathrm{Z}_{\max }(\mathrm{Pu})<80 \AA\right)$, which indicates that the driving force for the formation of Th-nanoparticles at the interface appears to be smaller, most likely due to Th(IV) being chemically softer and thus less prone to hydrolysis than $\mathrm{Pu}(\mathrm{IV})$.

Results from alpha spectrometry suggest that the particles may be partially removable. Uptake quantification performed $e x$ situ after two flushing steps finds a significantly smaller coverage of $\theta_{\alpha}=1.6 \pm 0.3 \mathrm{Th} / \mathrm{A}_{\mathrm{UC}}$ than the $\theta_{\mathrm{RAXR}}=4.9 \mathrm{Th} / \mathrm{A}_{\mathrm{UC}}$ found by RAXR. The plutonium nanoparticles reported previously were not desorbed by similar flushing steps, and RAXR and alpha spectrometry found matching coverages in these experiments (Schmidt et al., 2013; Schmidt et al., 2012b). For Th extended outer sphere complexes, however, it has been demonstrated that the sorption reaction is partly reversible (Schmidt et al., 2012a). 


\subsection{Potential mechanisms for background electrolyte effects}

There are two possible pathways for how the presence of $\mathrm{Li}^{+}$could influence the formation of the $\mathrm{Th}(\mathrm{IV})$ nanoparticles: by increasing the uptake of $\mathrm{Th}(\mathrm{IV})$ at the interface, or by catalyzing the formation of Th oligomers in solution. The adsorption isotherm measured for $\mathrm{Th}(\mathrm{IV})$ in the presence of $\mathrm{NaCl}$ shows a stark increase in Th coverage at concentrations larger than $10^{-3} \mathrm{~mol} / \mathrm{L}$ to more than $2 \mathrm{Th} / \mathrm{A}_{\mathrm{UC}}$, well beyond what is required for charge compensation. The increase has been associated with a surface precipitation reaction, even though all Th solid phases were undersaturated (Schmidt et al., 2012a). The precipitate has not been characterized, and the chemical state of $\mathrm{Th}(\mathrm{IV})$ at the interface at these higher concentrations remains unclear. On the other hand it was shown for $\mathrm{Pu}$ adsorption at the muscovite basal plane that the high interfacial concentrations in a charge compensating layer are sufficient to induce polymerization of even minor quantities of $\mathrm{Pu}(\mathrm{IV})$ in a solution of ostensibly $\mathrm{Pu}(\mathrm{III})$ (Schmidt et al., 2013). In these experiments small quantities of tetravalent $\mathrm{Pu}$ in a solution of trivalent $\mathrm{Pu}$ in contact with air lead to the formation of $\mathrm{Pu}(\mathrm{IV})$-oxonanoparticles at the interface, in part due to the enhanced concentration of plutonium in the nearinterface regime. Atomic force microscopy confirms that plutonium is present as discrete nanoparticles. Thorium's tendency to hydrolyze and polymerize is less pronounced than plutonium's (Knope and Soderholm, 2012), thus it is expected that Th only begins to polymerize at higher interfacial concentrations. Therefore the central question appears to be to understand what factors control the interfacial Th concentration and consequently allow it to become sufficiently high for nanoparticle formation at the interface.

A partial explanation for the cation effect may be found in the competitive adsorption behavior of Th and the "inert" background electrolyte, which is closely connected with their relative hydration energies. $\mathrm{Li}$ is the smallest alkali metal ion and has the corresponding largest hydration energy, and it decreases systematically within the group. Accordingly, recent results (Lee et al., 2012) have demonstrated that the adsorption enthalpy of these cations has a distinct non-monotonic dependence along the alkali series, where $\mathrm{Li}$ is more weakly bound than the heavier alkali cations (e.g., $\mathrm{Rb}$, and Cs). From this, it was inferred that it adsorbs on the muscovite surface as an outer-sphere species, while $\mathrm{Rb}$ and $\mathrm{Cs}$, for instance, are known to adsorb preferentially as IS species. Therefore a possible 
explanation for the observed cation effect on the Th sorption behavior is that the difference in the

511 background cation speciation and adsorption enthalpies may influence the adsorption structure and

512 coverage of Th by ability of the alkali cation to compete with Th for adsorption. This observation is

513 fully consistent with the observed systematic trend of an increasing Th coverage (at $0.1 \mathrm{M}$ background

514 electrolyte concentration) in the presence of $\mathrm{KClO}_{4}$ vs. $\mathrm{LiClO}_{4}$. What is not expected within this

515 model is the negligible adsorption of Th in the presence of $\mathrm{NaClO}_{4}$ at this concentration. A further test

516 of this idea could be obtained by additional Th adsorption studies at higher background electrolyte

517 concentrations. This picture predicts that Th precipitation would be inhibited for all background

518 electrolytes, but with a threshold concentration for inhibition that decreases from Li through $\mathrm{K}$ due to

519 the different adsorption enthalpies.

Lithium may also have an impact on the solution chemistry of Th. Lithium has been shown to enhance the formation of nanoparticles and oligomers of several actinides, amongst others $\mathrm{Th}$ and $\mathrm{Pu}$

522 (Knope and Soderholm, 2012; Soderholm et al., 2008). Hence, it is conceivable that the aqueous speciation of Th is modified in the presence of lithium towards a larger prevalence of oligomeric species. However, our interface-specific experiments do not probe the bulk solution speciation and no effect of lithium on bulk speciation has been documented in the available databases (Rand et al., 2008). There is some indication that lithium does not increase the formation of oligomers in chloride media, and does in fact hamper the underlying hydrolysis reaction with respect to sodium and potassium (Milic, 1981). In conclusion, additional research into the dependence of the aqueous speciation of Th on the background electrolyte will be required to resolve this question.

530 The effect of the anion is more challenging to understand. The comparison of the otherwise identical samples $\mathrm{Th}-\mathrm{NaCl}$ and $\mathrm{Th}-\mathrm{hiNaClO}{ }_{4}$ clearly shows that the presence of $\mathrm{ClO}_{4}{ }^{-}$reduces the uptake of Th(IV) to the mica basal plane with respect to that in $\mathrm{Cl}^{-}$media. A direct involvement of the perchlorate ion by complexation to the cation would reduce its charge and cause increased uptake at the interface, as more Th would be required to compensate the surface charge. Also, no inner sphere complexation of Th(IV) by $\mathrm{ClO}_{4}{ }^{-}$has been observed and no complexation constants are reported 536 (Rand et al., 2008). Complexation of $\mathrm{Th}$ with $\mathrm{ClO}_{4}{ }^{-}$can thus be ruled out as primary cause of the 
observed perchlorate effect. Also important to consider is the capacity of an ion to "make or break" water structure beyond its formal hydration shell (Marcus, 2009), with their relative influences expressed through the Hofmeister series (Hofmeister, 1888). Here, the electrolyte effect is not directly on the adsorbing cation, but rather sorption would be affected indirectly through differences in the water structure around the cation or on the interface. The theory as presented in the review by Marcus (Marcus, 2009) considers both $\mathrm{Cl}^{-}$and $\mathrm{ClO}_{4}{ }^{-}$to be "structure breaking" ions, but the effect is considered much stronger for $\mathrm{ClO}_{4}{ }^{-}$than for $\mathrm{Cl}^{-}$, so a possible explanation for the observed effects would be that the water structure at the interface or around Th(IV) is disturbed in a way that decreases the tendency for Th(IV) to adsorb. However, the observed behavior of the cations of the background electrolyte contradicts the systematics demonstrated in (Marcus, 2009). According to the study, $\mathrm{Li}^{+}$is a "structure making" ion, $\mathrm{Na}^{+}$is a borderline case, and $\mathrm{K}^{+}$is "structure breaking". Consequently, if breaking the water structure inhibits the adsorption of Th(IV), uptake of Th(IV) should follow the trend $\mathrm{Li}^{+}>\mathrm{Na}^{+}>\mathrm{K}^{+}$, and no adsorption should be observed for Th- $\mathrm{KClO}_{4}$ as is the case for ThhiNaClO 4 . While $\mathrm{Li}^{+}$appears to follow this trend and significantly increases $\mathrm{Th}(\mathrm{IV})$ uptake (see discussion above), $\mathrm{Th}(\mathrm{IV})$ uptake is in fact increased for Th- $\mathrm{KClO}_{4}$ compared to Th-hiNaClO 4 and even Th-loNaClO 4 . In addition, the total ED profiles derived from CTR (see Figure 3 and EA) show similar water layering close to the interface, nearly independent of the electrolyte. The theory of structure making and breaking ions is mainly built on data from biological systems (Hofmeister, 1888) and from ionic solutions at fairly high ionic strengths (Marcus, 2009), where such weak effects can be observed. It is then not surprising that under more dilute geochemical conditions other interactions, e.g. complexation or adsorption competition, may dominate.

The reversibility experiments show that the perchlorate effect on the Th adsorption is very slow, once $\mathrm{Th}(\mathrm{IV})$ has adsorbed to the interface from $\mathrm{NaCl}$ media. After one hour of reaction time with $\mathrm{NaClO}_{4}$ background no significant change occurs, and even after eight hours the adsorption structure has not changed dramatically. We cannot unambiguously assign the observed partial desorption to the change in background electrolyte in these experiments. The flushing solution did not contain Th(IV), 
conclude that the effect of the perchlorate ion on the sorption reaction occurs prior to the adsorption

565 step, and is less (or not at all) effective once sorption has happened.

\section{CONCLUSION}

567 The present results demonstrate that the sorption behavior of tetravalent Th onto the muscovite 568 (001) basal plane shows unexpected and strong sensitivity to the background electrolyte. Comparing to 569 the Th- $\mathrm{NaCl}$ system, we can differentiate two distinct regimes for the effects of perchlorate media: a 570 sorption inhibition regime for Th-hiNaClO${ }_{4}$ and to a lesser extent $\mathrm{Th}-\mathrm{loNaClO}_{4}$ and $\mathrm{Th}-\mathrm{KClO}_{4}$, and a 571 sorption enhancement effect for $\mathrm{Th}-\mathrm{LiClO}_{4}$. Both effects have been observed and quantified by RAXR 572 and alpha spectrometry. It was possible to exclude complexation reactions, and chaotropic effects of 573 the ions (Hofmeister series), as the underlying mechanism of the effect. While the effect of the 574 background electrolyte cation might be explained by competitive adsorption (due to the different 575 adsorption enthalpies of $\mathrm{K}$ vs. $\mathrm{Li}$, for instance), this explanation is not necessarily unique. A 576 straightforward deduction a single mechanism, especially as regards to the role of anions, is as yet not 577 possible and will require further studies. It is plausible that the identified effects are in fact not the 578 consequence of a single mechanism, but a convolution of several effects in solution and at the 579 interface. That notwithstanding, the presented data draw attention to the importance of ionic effects on 580 (geo-)chemical reactions, given the large differences between the most commonly applied electrolytes $-\mathrm{NaCl}$ and $\mathrm{NaClO}_{4}-$ in this system.

\section{ACKNOWLEDGEMENTS}

This work was co-financed (M.S. and S.H.) by the Helmholtz Gemeinschaft Deutscher

584 Forschungszentren by supporting the Helmholtz-Nachwuchsgruppe "Structures and Reactivity at the 585 Water/Mineral Interface" (VH-NG-942). Work conducted at Argonne National Laboratory, operated 586 by UChicago Argonne, LLC for the United States Department of Energy under contract number DE587 AC02-06CH11357, is supported by the United States Department of Energy Office of Science BES 588 Chemical Sciences Division [Geoscience (S.S.L. and P.F.) and Heavy Elements (K.E.K. and L.S.) 589 research programs]. The X-ray data were collected at the GeoSoilEnviroCARS beamline 13-ID-C and 
the X-ray Operations and Research beamline 6-ID-B at the Advanced Photon Source (APS), Argonne

National Laboratory. GeoSoilEnviro-CARS is supported by the National Science Foundation-Earth

Sciences (EAR-1128799) and Department of Energy-Geosciences (DE-FG02-94ER14466) (J.E.S. and

P.J.E). We thank Dr. S. Skanthakumar for his assistance in preparation of XR samples.

References

Baes, C.F., Bjerrum, J., Schwarzenbach, G., Sillen, L.G., 1958. Part II, Inorganic Ligands, Stability Constants. The Chemical Society, London.

Baes, C.F., Mesmer, R.E., 1976. The hydrolysis of cations. John Wiley \& Sons Inc., New Jersey.

Brown, P.L., Ellis, J., Sylva, R.N., 1983. The hydrolysis of metal ions. Part 5. Thorium(IV). Journal of the Chemical Society, Dalton Transactions, 31-34.

Burgess, J., 1978. Metal ions in solution. Ellis Horwood Ltd., Chichester, U.K.

Catalano, J.G., Park, C., Fenter, P., Zhang, Z., 2008. Simultaneous inner- and outer-sphere arsenate adsorption on corundum and hematite. Geochimica et Cosmochimica Acta 72, 1986-2004.

Cheng, L., Fenter, P., Nagy, K.L., Schlegel, M.L., Sturchio, N.C., 2001. Molecular-Scale Density Oscillations in Water Adjacent to a Mica Surface. Physical Review Letters 87, 156103.

Choppin, G.R., Jensen, M.P., 2011. Actinides in Solution: Complexation and Kinetics, in: Morss, L.R., Edelstein, N.M., Fuger, J., Katz, J.J. (Eds.), The Chemistry of the Actinide and Transactinide Elements, 4th ed. Springer, pp. 2524-2621.

Cross, J.O., Newville, M., Rehr, J.J., Sorensen, L.B., Bouldin, C.E., Watson, G., Gouder, T., Lander, G.H., Bell, M.I., 1998. Inclusion of local structure effects in theoretical x-ray resonant scattering amplitudes using ab initio x-ray-absorption spectra calculations. Physical Review B 58, 11215.

Eikenberry, E.F., Brönnimann, C., Hülsen, G., Toyokawa, H., Horisberger, R., Schmitt, B., Schulze-Briese, C., Tomizaki, T., 2003. PILATUS: a two-dimensional X-ray detector for macromolecular crystallography. Nuclear Instruments and Methods in Physics Research Section A: Accelerators, Spectrometers, Detectors and Associated Equipment 501, 260-266.

Ekberg, C., Albinsson, Y., Comarmond, M.J., Brown, P.L., 2000. Studies on the complexation behavior of thorium(IV). 1. Hydrolysis equilibria. J. Sol. Chem. 29, 63-86. 
Feidenhans'1, R., 1989. Surface-Structure Determination by X-Ray-Diffraction. Surface Science Reports 10, 105-188.

Felmy, A.R., Rai, D., Mason, M.J., 1991. The solubility of hydrous thorium(IV) oxide in chloride media: development of an aqueous ion-interaction model. Radiochimica Acta 55, 177-185.

Fenter, P., 2002. X-ray Reflectivity as a Probe of Mineral-Fluid Interfaces: A User Guide. Reviews in Mineralogy and Geochemistry 49, 149-220.

Fenter, P., Lee, S.S., Park, C., Soderholm, L., Wilson, R.E., Schwindt, O., 2010. Interaction of muscovite $\left(\begin{array}{lll}0 & 0 & 1\end{array}\right)$ with $\mathrm{Pu}^{3+}$ bearing solutions at $\mathrm{pH} 3$ through ex-situ observations. Geochimica et Cosmochimica Acta 74, 6984-6995.

Fenter, P.A., Park, C., Nagy, K.L., Sturchio, N.C., 2007. Resonant anomalous X-ray reflectivity as a probe of ion adsorption at solid-liquid interfaces. Thin Solid Films 515, 5654-5659.

Guo, Z., Niu, L., Tao, Z., 2005. Sorption of Th(IV) ions onto $\mathrm{TiO}_{2}$ : Effects of contact time, ionic strength, thorium concentration and phosphate. Journal of Radioanalytical and Nuclear Chemistry 266, 333-338.

Hofmann, S., Voïtchovsky, K., Schmidt, M., Stumpf, T., 2014. Trace concentration - Huge impact: Nitrate in the calcite/Eu(III) system. Geochimica et Cosmochimica Acta 125, 528-538.

Hofmeister, F., 1888. Zur Lehre von der Wirkung der Salze. Archiv für experimentelle Pathologie und Pharmakologie 24, 247-260.

Hummel, W., Berner, U., Curti, E., Thoenen, T., Pearson, F.J., 2002. The NAGRA/PSI Chemical Thermodynamic Database 01/01. Radiochimica Acta 90, 805-813.

Israelachvili, J., Wennerstrom, H., 1996. Role of hydration and water structure in biological and colloidal interactions. Nature 379, 219-225.

Jakobsson, A.-M., 1999. Measurement and Modeling of Th Sorption onto TiO2. Journal of Colloid and Interface Science 220, 367-373.

Knope, K.E., Soderholm, L., 2012. Solution and Solid-State Structural Chemistry of Actinide Hydrates and Their Hydrolysis and Condensation Products. Chemical Reviews 113, 944-994.

Knope, K.E., Wilson, R.E., Vasiliu, M., Dixon, D.A., Soderholm, L., 2011. Thorium(IV) molecular clusters with a hexanuclear Th core. Inorg. Chem. 50, 9696-9704.

Landa, E.R., Le, A.H., Luck, R.L., Yeich, P.J., 1995. Sorption and coprecipitation of trace concentrations of thorium with various minerals under conditions simulating an acid uranium mill effluent environment. Inorganica Chimica Acta 229, 247-252.

Lee, S.S., Fenter, P., Nagy, K.L., Sturchio, N.C., 2012. Monovalent ion adsorption at the muscovite (001) - solution interface: Relationships among ion coverage and speciation, interfacial water structure, and substrate relaxation. Langmuir 28, 8637-8650.

Lee, S.S., Fenter, P., Nagy, K.L., Sturchio, N.C., 2013a. Changes in adsorption free energy and speciation during competitive adsorption between monovalent cations at the muscovite (001)- water interface. Geochimica et Cosmochimica Acta 123, 416-426.

Lee, S.S., Fenter, P., Park, C., 2013b. Optimizing a flow-through X-ray transmission cell for studies of temporal and spatial variations of ion distributions at mineral-water interfaces. Journal of Synchrotron Radiation 20, 125-136. 
Lee, S.S., Fenter, P., Park, C., Sturchio, N.C., Nagy, K.L., 2010. Hydrated Cation Speciation at the Muscovite (001)-Water Interface. Langmuir 26, 16647-16651.

Lee, S.S., Nagy, K.L., Fenter, P., 2007. Distribution of barium and fulvic acid at the micasolution interface using in-situ X-ray reflectivity. Geochimica et Cosmochimica Acta 71, 5763-5781.

Lee, S.S., Nagy, K.L., Park, C., Fenter, P., 2009. Enhanced Uptake and Modified Distribution of Mercury(II) by Fulvic Acid on the Muscovite (001) Surface. Environmental Science \& Technology 43, 5295-5300.

Lee, S.S., Schmidt, M., Laanait, N., Sturchio, N.C., Fenter, P., 2013c. Investigation of Structure, Adsorption Free Energy, and Overcharging Behavior of Trivalent Yttrium Adsorbed at the Muscovite (001)-Water Interface. The Journal of Physical Chemistry C 117, 23738-23749.

Li, W., Tao, Z., 2002. Comparative study on Th(IV) sorption on alumina and silica from aqueous solution. Journal of Radioanalytical and Nuclear Chemistry 254, 187-192.

Marcus, Y., 2009. Effect of Ions on the Structure of Water: Structure Making and Breaking. Chemical Reviews 109, 1346-1370.

Milic, N.B., 1981. Linear free-energy relationships in the hydrolysis of metal ions. The effect of the ionic medium. Journal of the Chemical Society, Dalton Transactions, 1445-1449.

Neck, V., Kim, J.I., 2001. Solubility and hydrolysis of tetravalent actinides. Radiochimica Acta 89, 1-16.

Neck, V., Muller, R., Bouby, M., Altmaier, M., Rothe, J., Denecke, M.A., Kim, J.I., 2002. Solubility of amorphous Th(IV) hydroxide - application of LIBD to determine the solubility product and EXAFS for aqueous speciation. Radiochimica Acta 90, 485-494.

Oelkers, E.H., Schott, J., Gauthier, J.-M., Herrero-Roncal, T., 2008. An experimental study of the dissolution mechanism and rates of muscovite. Geochimica et Cosmochimica Acta 72, 4948-4961.

Östhols, E., 1995. Thorium sorption on amorphous silica. Geochimica et Cosmochimica Acta 59, 1235-1249.

Östhols, E., Manceau, A., Farges, F., Charlet, L., 1997. Adsorption of Thorium on Amorphous Silica: An EXAFS Study. Journal of Colloid and Interface Science 194, 10-21.

Park, C., Fenter, P., 2007. Phasing of Resonant Anomalous X-ray Reflectivity Spectra and Direct Fourier Synthesis of Element-Specific Partial Structures at Buried Interfaces. Journal of Applied Crystallography 40, 290-301.

Park, C., Fenter, P.A., Nagy, K.L., Sturchio, N.C., 2006. Hydration and Distribution of Ions at the Mica-Water Interface. Physical Review Letters 97, 016101.

Parkhurst, D.L., Appelo, C.A.J., 1999. User's Guide to PHREEQC (Version 2) - A Computer Program for Speciation, Batch-Reaction, One-Dimensional Transport and Inverse Geochemical Calculations, Water-Resources Investigations Report 99-4259. U.S. Geological Survey, Denver, CO.

Pashley, R.M., 1981. DLVO and hydration forces between mica surfaces in $\mathrm{Li}+, \mathrm{Na}+, \mathrm{K}+$, and Cs+ electrolyte solutions: A correlation of double-layer and hydration forces with surface cation exchange properties. Journal of Colloid and Interface Science 83, 531-546.

Pashley, R.M., 1982. Hydration Forces between Mica Surfaces in Electrolyte-Solutions. Advances in Colloid and Interface Science 16, 57-62. 
Rand, M., Fuger, J., Neck, V., Grenthe, I., Rai, D., 2008. Chemical Thermodynamics of Thorium. North Holland Elsevier Science B.V., Amsterdam, The Netherlands.

Reiller, P., Casanova, F., Moulin, V., 2005. Influence of Addition Order and Contact Time on Thorium(IV) Retention by Hematite in the Presence of Humic Acids. Environmental Science \& Technology 39, 1641-1648.

Robinson, I.K., Tweet, D.J., 1992. Surface X-ray-Diffraction. Reports on Progress in Physics 55, 599-651.

Rojo, I., Seco, F., Rovira, M., Giménez, J., Cervantes, G., Martí, V., de Pablo, J., 2009. Thorium sorption onto magnetite and ferrihydrite in acidic conditions. Journal of Nuclear Materials 385, 474478.

Rothe, J., Denecke, M.A., Neck, V., Müller, R., Kim, J.I., 2002. XAFS Investigation of the Structure of Aqueous Thorium(IV) Species, Colloids, and Solid Thorium(IV) Oxide/Hydroxide. Inorganic Chemistry 41, 249-258.

Ryan, J.L., Rai, D., 1987. Thorium(IV) hydrous oxide solubility. Inorganic Chemistry 26, 41404142.

Schlegel, M.L., Nagy, K.L., Fenter, P., Cheng, L., Sturchio, N.C., Jacobsen, S.D., 2006. Cation sorption on the muscovite $\left(\begin{array}{lll}0 & 0 & 1\end{array}\right)$ surface in chloride solutions using high-resolution X-ray reflectivity. Geochimica et Cosmochimica Acta 70, 3549-3565.

Schmidt, M., Eng, P., Stubbs, J., Soderholm, L., Fenter, P., 2011. On a new X-ray reflectivity environmental cell design for in situ studies of radioactive and atmosphere-sensitive samples. Review of Scientific Instruments 82, 075105-1 - 075105-10.

Schmidt, M., Lee, S.S., Wilson, R.E., Knope, K.E., Bellucci, F., Eng, P.J., Stubbs, J.E., Soderholm, L., Fenter, P., 2013. Surface-Mediated Formation of Pu(IV) Nanoparticles at the Muscovite-Electrolyte Interface. Environmental Science \& Technology 47, 14178-14184.

Schmidt, M., Lee, S.S., Wilson, R.E., Soderholm, L., Fenter, P., 2012a. Sorption of tetravalent Thorium on Muscovite. Geochimica et Cosmochimica Acta 88, 66-76.

Schmidt, M., Wilson, R.E., Lee, S.S., Soderholm, L., Fenter, P., 2012b. Adsorption of plutonium oxide nanoparticles. Langmuir 28, 2620-2627.

Sharma, P., Singh, G., Tomar, R., 2009. Synthesis and characterization of an analogue of heulandite: Sorption applications for thorium(IV), europium(III), samarium(II) and iron(III) recovery from aqueous waste. Journal of Colloid and Interface Science 332, 298-308.

Sharma, P., Tomar, R., Sharma, P., Tomar, R., 2006. Sorption and desorption of $\mathrm{UO}_{2}{ }^{2+}, \mathrm{Th}^{4+}$ and $\mathrm{Ru}^{3+}$ on the synthetic analogue of muscovite. Journal of Radioanalytical and Nuclear Chemistry 268, 329-336.

Sheng, G., Hu, J., Wang, X., 2008. Sorption properties of Th(IV) on the raw diatomite--Effects of contact time, $\mathrm{pH}$, ionic strength and temperature. Applied Radiation and Isotopes 66, 1313-1320.

Soderholm, L., Almond, P.M., Skanthakumar, S., Wilson, R.E., Burns, P.C., 2008. The structure of the plutonium oxide nanocluster $\left[\mathrm{Pu}_{38} \mathrm{O}_{56} \mathrm{Cl}_{54}\left(\mathrm{H}_{2} \mathrm{O}\right)_{(8)}\right]^{(14-)}$. Angewandte Chemie-International Edition 47, 298-302.

Talip, Z., Eral, M., Hiçsönmez, Ü., 2009. Adsorption of thorium from aqueous solutions by perlite. Journal of Environmental Radioactivity 100, 139-143. 
Walther, C., Fuss, M., Buchner, S., 2008. Formation and hydrolysis of polynuclear Th(IV) complexes - a nano-electrospray mass-spectrometry study. Radiochimica Acta 96, 411-425.

745

746

747

752
Wickleder, M.S., Fourest, B., Dorhout, P.K., 2011. Thorium, in: Morss, L.R., Edelstein, N.M., Fuger, J., Katz, J.J. (Eds.), The Chemistry of the Actinide and Transactinide Elements, 4th ed. Springer, pp. 52-160.

Wilson, R.E., 2011. Structural periodicity in plutonium(IV) sulfates. Inorg. Chem. 50, 5663-5670.

Wilson, R.E., Schwindt, O., Fenter, P., Soderholm, L., 2010. Exploitation of the sorptive properties of mica for the preparation of higher-resolution alpha-spectroscopy samples. Radiochimica Acta 98, 431-436.

Wilson, R.E., Skanthakumar, S., Sigmon, G., Burns, P.C., Soderholm, L., 2007. Structures of dimeric hydrolysis products of thorium. Inorganic Chemistry 46, 2368-2372.

Zhang, H., Zheng, D., Tao, Z., 2006. Sorption of thorium(IV) ions on gibbsite: Effects of contact time, $\mathrm{pH}$, ionic strength, concentration, phosphate and fulvic acid. Colloids and Surfaces A:

Physicochemical and Engineering Aspects 278, 46-52. 